\title{
Is the SF-36 a valid measure of quality of life following percutaneous endoscopic gastrostomy (PEG) placement? A feasibility study
}

\author{
A. M. Brotherton and M. Hurley \\ University of Central Lancashire, Preston PRI 2HE, UK
}

The SF-36 is often considered to be a gold standard measure of quality of life and several authors have attempted to measure quality of life using this questionnaire, in patients receiving PEG feeding with inconclusive results ${ }^{(1,2)}$ and minimal questioning of the suitability of the tool. This feasibility study aimed to assess the appropriateness of the SF-36, both as a self-rating and proxy measure of quality of life in patients following gastrostomy insertion. Statistical analyses were conducted using SPSS for Windows and descriptive statistics in the form of median values and ranges are presented (Table).

Prior to PEG placement demographic and clinical data were recorded for thirteen male and nine female patients, mean age 70 (range 34-96) years. Where possible the patients and their primary carers were asked to complete the SF-36 prior to PEG insertion (baseline), at 1 week and 1-, 3- and 6-month intervals post-placement. Twenty-two sets of completed SF-36 questionnaires were obtained. Outcomes at 6 months were poor; thirteen $(59 \%)$ patients had died, seven (32\%) were still receiving feeds and only two (9\%) had resumed oral diet.

\begin{tabular}{|c|c|c|c|c|c|c|c|c|c|c|}
\hline \multirow[b]{2}{*}{ Category } & \multicolumn{5}{|c|}{ Patients } & \multicolumn{5}{|c|}{ Primary Carers } \\
\hline & $\begin{array}{c}\text { Baseline } \\
n 6\end{array}$ & $\begin{array}{c}1 \text { week } \\
n 6\end{array}$ & $\begin{array}{c}1 \text { month } \\
n 4\end{array}$ & $\begin{array}{c}3 \text { months } \\
n 1\end{array}$ & $\begin{array}{c}6 \text { months } \\
n 1\end{array}$ & $\begin{array}{l}\text { Baseline } \\
n 16\end{array}$ & $\begin{array}{c}1 \text { week } \\
n 16\end{array}$ & $\begin{array}{c}1 \text { month } \\
n 11\end{array}$ & $\begin{array}{c}3 \text { months } \\
n 8\end{array}$ & $\begin{array}{c}6 \text { months } \\
n 7\end{array}$ \\
\hline Physical functioning & $5(0-20)$ & $0(0-10)$ & $2.5(0-60)$ & 0 & 0 & $0(0-70)$ & $0(0-65)$ & $0(0-55)$ & $0(0-5)$ & $0(0-5)$ \\
\hline Role physical & $0(0-0)$ & $0(0-0)$ & $0(0-0)$ & 0 & 0 & $0(0-25)$ & $0(0-0)$ & $0(0-50)$ & $0(0-0)$ & $0(0-0)$ \\
\hline Pain & $94(44-100)$ & $50(33-100)$ & $89(66-100)$ & 100 & 100 & $72(33-100)$ & $78(44-100)$ & $78(44-100)$ & $89(11-100)$ & $78(44-100)$ \\
\hline General health & $55(25-95)$ & $35(25-75)$ & $28(15-65)$ & 30 & 56 & $20(0-55)$ & $15(0-55)$ & $25(5-50)$ & $28(10-50)$ & $25(0-55)$ \\
\hline Vitality & $38(15-45)$ & $28(0-45)$ & $35(20-60)$ & 45 & 45 & $20(0-40)$ & $13(0-45)$ & $15(0-55)$ & $33(0-55)$ & $30(0-60)$ \\
\hline Social functioning & $25(0-25)$ & $13(0-38)$ & $63(0-63)$ & 13 & 13 & $0(0-63)$ & $0(0-63)$ & $0(0-88)$ & $0(0-100)$ & $0(0-88)$ \\
\hline Role emotional & $50(0-100)$ & $0(0-100)$ & $50(0-100)$ & 0 & 0 & $0(0-100)$ & $0(0-100)$ & $0(0-100)$ & $0(0-100)$ & $0(0-100)$ \\
\hline Mental health & $64(44-88)$ & $66(36-80)$ & $63(56-88)$ & 56 & 56 & $42(0-84)$ & $52(0-84)$ & $56(20-80)$ & $58(8-84)$ & $60(8-80)$ \\
\hline Changes in health & $25(0-50)$ & $25(0-50)$ & $25(0-50)$ & 25 & 25 & $0(0-50)$ & $0(0-50)$ & $0(0-50)$ & $0(0-25)$ & $0(0-25)$ \\
\hline
\end{tabular}

Distribution of the data was markedly skewed with a high proportion of the patient and carer scores demonstrating floor effects i.e. a score of between 0 and $10 \%$ clearly demonstrating that the SF-36 was an unsuitable tool for measuring quality of life in this population.

The SF-36 represents a concise yet comprehensive thirty-six-item questionnaire. The measure was designed to detect both the presence and absence of problems in addition to the degree of difficulty experienced, ranging from good health to poor health. In summary, the patients in this population were too poorly for the SF-36 to have the sensitivity or specificity to evaluate quality of life.

1. Bannerman E, Pendlebury J, Phillips F \& Ghosh, S (2000). Eur J Gastroenterol Hepatol. 12 (10), 1101-1109.

2. Schneider SM, Pouget I., Staccini P, Rampal P \& Hebuterne X (2000) Clin Nutr, 19 (1), 23-28. 